\title{
Farklı Sulama Suyu Kalitesi ve Su Düzeylerinin Serada Yetiştirilen Domates Bitkisinin Verim ve Su Kullanım Etkinliği Üzerine Etkisi
}

\author{
Ülviye KAMBUROĞLU ÇEBi ${ }^{1 *}$, Selçuk ÖZER ${ }^{1}$, Süreyya ALTINTAŞ ${ }^{2}$ \\ Ozan ÖZTÜRK ${ }^{1}$, Engin YURTSEVEN ${ }^{3}$
}

\author{
${ }^{1}$ Atatürk Toprak Su ve Tarımsal Meteoroloji Araştırma Enstitüsü Müdürlüğü, KIRKLARELi \\ [ORCID:https://orcid.org/0000-0002-1587-6318 (U.K. ÇEBi), 0000-0002- 6055-4377 (S. ÖZER), 0000- \\ 0001- 8329-2739 (O. ÖZTÜRK)] \\ ${ }^{2}$ Namık Kemal Üniversitesi Ziraat Fakültesi Bahçe Bölümü, TEKIRDAĞ [ORCID:https://orcid.org/0000- \\ 0001-9781-2870] \\ ${ }^{3}$ Ankara Üniversitesi Ziraat Fakültesi Tarımsal Yapılar ve Sulama Bölümü, ANKARA \\ [ORCID:https://orcid.org/0000-0001-6789-8810] \\ *Sorumlu yazar:ulviyecebi@yahoo.com, ulviye.kcebi@tarim.gov.tr
}

Öz

Farklı tuzluluk seviyelerinde ve farklı düzeylerde uygulanan sulama sularının domateste pazarlanabilir meyve verimi ve su kullanım etkinliği üzerine etkisinin araştırıldı̆ı çalışma, 2014, 2015 ve 2016 yılları ilkbahar-yaz yetiştirme periyodunda, Kırklareli Atatürk Toprak Su ve Tarımsal Meteoroloji Araştırma Enstitüsü arazisinde kurulu olan yay çatılı ısıtmasız serada yürütülmüştür. Çalışmada dört sulama suyu tuzluluğu; T1: $0.38 \mathrm{dS} \mathrm{m}^{-1}, \mathrm{T2}: 1.10 \mathrm{dS} \mathrm{m}^{-1}, \mathrm{T3}: 2.50 \mathrm{dS} \mathrm{m}^{-1}$, T4: $5.00 \mathrm{dS} \mathrm{\textrm {m } ^ { - 1 }}$ ile üç sulama seviyesi; profildeki eksilen neme göre tarla kapasitesinin \%70'i (S1), \%100'ü (S2) ve \%130'u (S3) seviyesinde sulama uygulamaları bölünmüş parseller deneme desenine göre 3 tekerrürlü olarak ele alınmışır. Profilde eksilen nem toprağın $0-20 \mathrm{~cm}, 20-40 \mathrm{~cm}, 40-60 \mathrm{~cm}$ ve $60-100 \mathrm{~cm}$ derinliklerine yerleştirilen nem sensörleri ile belirlenmiştir. Üç yılın ortalamasına göre uygulanan su miktarları sırasıyla 240 (S1), 334 (S2) ve $429 \mathrm{~mm}$ (S3) olmuştur. Bitki su tüketimi değerleri $248 \mathrm{~mm}$ ile $453 \mathrm{~mm}$ arasında değişmekle beraber en yüksek su tüketimi T1S3 konusunda, en düşük su tüketimi T4S1 konusunda belirlenmiştir. En yüksek verimler T1S2, T2S2 ve T1S3 uygulamalarından, en düşük verim ise T4S1 uygulamasından elde edilmiştir. Sulama suyu tuzluluğu arttıkça her sulama düzeyinde verim ve pazarlanabilir verime göre su kullanım randımanı (WUE) düşmüştür.

Anahtar Kelimeler: Domates, Tuzluluk, Su kullanım randımanı, Pazarlanabilir verim

\author{
Effect of Different Irrigation Levels and Irrigation Water Salinity \\ on Water Use Efficiency and Yield of Tomato Grown in Greenhouse
}

\begin{abstract}
A three-year study was carried out to investigate the combining effect of irrigation water salinity and irrigation levels on the marketable yield and water use efficiency of tomato grown in Quonset type, unheated, PE greenhouse in Kırklareli Atatürk Soil Water and Agricultural Meteorology Research Institute during 2014, 2015 and 2016 spring-summer crop cycle. Four irrigation water salinity levels; T1: $0.38 \mathrm{dS} \mathrm{m}^{-1}, \mathrm{~T} 2: 1.10 \mathrm{dS} \mathrm{m}^{-1}, \mathrm{~T} 3: 2.50 \mathrm{dS} \mathrm{m}^{-1}, \mathrm{~T} 4: 5.00 \mathrm{dS} \mathrm{m}^{-1}$ and three irrigation levels; restoring $70 \%$ (S1), $100 \%$ (S2) and $130 \%$ (S3) of water volume at field capacity were studied in split-plot design with three replications. Required water volume for each irrigation was determined according to data from probes located in different depth of soil for estimating soil moisture content. Amount of irrigation water applied to S1, S2 and S3 treatments were 240,334 and $429 \mathrm{~mm}$, respectively. Plant water consumption values varied between 248 and $453 \mathrm{~mm}$ and the highest and lowest water consumptions were measured in T1S3 and T4S1 treatments, respectively. Marketable yield of tomato was effected by both electrical conductivity of water and irrigation water amount. According to combining effect of both
\end{abstract}


factor over three years, the highest yields were obtained from T1S2, T2S2 and T1S3 treatments while the lowest yield was obtained from T4S1 treatment. Water use efficiency (WUE) of tomato reduced with increased EC of irrigation water in all irrigation managements.

Key Words: Tomato, Salinity, Irrigation level, WUE, Marketable yield

\section{Giriş}

Serada yıl boyu üretim yapılması, karlılığı yüksek türlerin tercih edilmesi, hep aynı türün veya beslenme istekleri benzer türlerin yetiştirilmesi, ürün nöbetine yer verilmemesi, yoğun gübreleme ve sulama yanında, drenaj sistemlerinin yeterli olmayışı ve yağışlara kapalı oluşu nedeniyle yıkanmanın olmayışı gibi faktörler tuzluluk problemi yaratmaktadır. Bu nedenle sera yapılarında yeterli suyun sağlanması yanında sulama suyunun kalitesi büyük önem kazanmaktadır. Diğer yandan, tüm dünyada olduğu gibi, ülkemizin sahip olduğu su kaynaklarının sınırlı oluşu ve suya olan talepte gözlenen artışın yanında küresel ısınma ile ortaya çıkması beklenen olumsuzluklar sahip olduğumuz su kaynaklarının daha randımanlı kullanımını zaruri hale getirmektedir. Bu nedenle, bitkilerin farklı sulama suyu tuzluluklarında ve sulama seviyelerinde davranışlarının belirlenmesi; verim ve kalite kaybı olmadan su kullanım etkinliğinin arttırıması ve tuzlu suların tarımda kullanılması konularında yeni stratejilerin ve metotların geliştirilmesi önemlidir.

Su kaynaklarının kısıtlı olduğu, plansız ve hızlı gelişen sanayi sektörü nedeniyle tarıma ayrılan suyun giderek azaldığı ve kalitesinin bozulduğu buna karşın örtüaltı yetiştiriciliğinin gün geçtikçe yaygınlaştığı Trakya Bölgesinde, bitkilerde farklı tuz stresi seviyelerinde elde edilecek verim ve kalitedeki değişim değerleri, sürdürülebilir su kullanımı ve yönetimi açısından önemlidir.

Geniş bir iklim kuşağında yetişebilen domates toprak istekleri bakımından da, fazla seçici bir bitki değildir. Ancak toprak tuzluluğuna karşı orta hassasiyet gösterir ve toprak çözeltisinin EC'si $2.5 \mathrm{dS} \mathrm{m}^{-1}$ i geçtiği zaman domateste meyve verimi düşmeye başlar (Tülücü, 2003). Fizyolojisi ve genetiği hakkındaki zengin bilgi varlığından dolayı domates bitkisi tuzlu alanların iyileştirilmesinde ve kötü kaliteli suların kullanımında model bitki olarak kullanılabilmektedir (Cuartero ve Fernandez-Munoz, 1999).

$\mathrm{Bu}$ çalışmada, farklı tuzluluk seviyelerinde ve farklı düzeylerde uygulanan sulama sularının sera domates yetiştiriciliğinde meyve verimi ve su kullanım etkinliği üzerine etkisi incelenmiştir.

\section{Materyal ve Metot}

Araştırma, Marmara Bölgesi'nin kuzey kısmında yer alan Kırklareli îlinin 4 km batısında bulunan Atatürk Toprak, Su ve Tarımsal Meteoroloji Araştırma Enstitüsü arazisinde kurulu, $608 \mathrm{~m}^{2}$ lik alana sahip olan $(76 \mathrm{~m} \times 8 \mathrm{~m})$ ve kuzey-güney 
doğrultusunda konumlandırılan yay çatılı, plastik örtülü serada 2014, 2015 ve 2016 yıllarında erken ilkbahar-yaz yetiştirme döneminde yürütülmüştür.

ilin uzun yıllar iklim verilerine göre; yıllık ortalama sıcaklık $13.0{ }^{\circ} \mathrm{C}$, maksimum sıcaklık $41.6{ }^{\circ} \mathrm{C}$ ve minimum sıcaklık $-15.8{ }^{\circ} \mathrm{C}$ olarak gerçekleşmiştir.
En sıcak aylar Haziran $\left(23.3{ }^{\circ} \mathrm{C}\right)$ ve Temmuz $\left(22.6{ }^{\circ} \mathrm{C}\right)$, en soğuk aylar Ocak $\left(2.6{ }^{\circ} \mathrm{C}\right)$ ve Şubat $\left(3.9{ }^{\circ} \mathrm{C}\right)$ aylarıdır. Denemenin yürütüldüğü döneme ait sera içi aylık ortalama, maksimum ve minimum sıcaklık ve nem değerleri (2014, 2015 ve 2016 yılların ortalaması) Çizelge 1 'de verilmiştir.

Çizelge 1. Denemenin yürütüldüğü 2014, 2015 ve 2016 yıllarına ait sera içi iklim değerleri (değerler üç yılın ortalamasıdır)

Table 1. Main monthly climate parameters in the greenhouse during tomato cropping cycle in 2014, 2015 and 2016 (values are means of three years)

\begin{tabular}{lcccccc}
\hline \multirow{3}{*}{$\begin{array}{l}\text { Aylar } \\
\text { Months }\end{array}$} & \multicolumn{3}{c}{ Sicaklık $\left({ }^{\circ} \mathrm{C}\right)$} & \multicolumn{3}{c}{ Oransal Nem (\%) } \\
& Mak. & Min. & Ort. & Mak. & Min. & Ort. \\
& Max. & Min. & Mean & Max & Min. & Mean \\
\cline { 2 - 7 } & 43.0 & 3.0 & 19.7 & 97.0 & 14.0 & 61.0 \\
\hline Nisan April & 43.1 & 8.4 & 21.9 & 95.0 & 23.0 & 65.3 \\
\hline Mayıs May & 42.4 & 9.8 & 24.7 & 96.5 & 31.5 & 70.3 \\
\hline Haziran June & 39.6 & 13.4 & 25.4 & 97.0 & 30.0 & 68.6 \\
\hline Temmuz July & 41.2 & 12.9 & 25.0 & 97.0 & 30.0 & 69.4 \\
\hline Ağustos August & 41.3 & 8.8 & 23.05 & 98.0 & 19.0 & 75.2 \\
\hline Eylül September & & & & & & \\
\hline
\end{tabular}

Araştırma serası, Alüviyal BTG ile kaplı arazi üzerine kurulmuştur. Alüviyal topraklar bulundukları iklime uyabilen her türlü kültür bitkisinin yetiştirilmesine elverişli ve üretken topraklardır.
Araştırma serası toprağının bazı fiziksel ve kimyasal özellikleri Çizelge 2'de; sulamada kullanılan suların özellikleri Çizelge 3'te verilmiştir.

Çizelge 2. Araştırma serası toprağının deneme öncesi bazı fiziksel ve kimyasal özellikleri Table 2. Some physical and chemical characteristics of the experimental soil

\begin{tabular}{|c|c|c|c|c|c|c|}
\hline \multicolumn{7}{|c|}{$\begin{array}{l}\text { Fiziksel özellikler } \\
\text { Physical properties }\end{array}$} \\
\hline Derinlik & Hacim ağırlığı & Kil & Silt & Kum & TK & SN \\
\hline $\begin{array}{l}\text { Depth } \\
(\mathrm{cm})\end{array}$ & $\begin{array}{l}\text { Bulk density } \\
\quad\left(\mathrm{g} \mathrm{cm}^{-3}\right)\end{array}$ & $\begin{array}{l}\text { Clay } \\
(\%)\end{array}$ & $\begin{array}{c}\text { Loam } \\
(\%)\end{array}$ & $\begin{array}{c}\text { Sand } \\
(\%)\end{array}$ & $\begin{array}{c}F C \\
(\mathrm{Pw})\end{array}$ & $\begin{array}{l}W P \\
(\mathrm{PW})\end{array}$ \\
\hline $0-30$ & 1.46 & 16.31 & 32.62 & 51.07 & 16.54 & 7.36 \\
\hline $30-60$ & 1.49 & 14.19 & 18.24 & 67.57 & 14.43 & 7.26 \\
\hline $60-90$ & 1.49 & 26.53 & 26.53 & 46.94 & 20.52 & 9.93 \\
\hline $90-120$ & 1.48 & 30.97 & 22.70 & 46.33 & 24.51 & 14.06 \\
\hline \multicolumn{7}{|c|}{$\begin{array}{l}\text { Kimyasal özellikler } \\
\text { Chemical properties }\end{array}$} \\
\hline & $\mathrm{pH}$ & 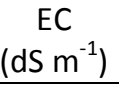 & $\begin{array}{l}\text { OM } \\
(\%) \\
\end{array}$ & \multicolumn{2}{|c|}{$\begin{array}{c}\mathrm{P}_{2} \mathrm{O}_{5} \\
\left(\mathrm{~kg} \mathrm{da}^{-1}\right)\end{array}$} & $\begin{array}{c}\mathrm{K}_{2} \mathrm{O} \\
\left(\mathrm{kg} \mathrm{da}^{1}\right)\end{array}$ \\
\hline $0-30$ & 7.42 & 0.059 & 1.35 & \multicolumn{2}{|c|}{8.93} & 50.5 \\
\hline
\end{tabular}


Çizelge 3. Araştırmada kullanılan suların bazı özellikleri

Table 3. Some characteristics of the irrigation water used in the experiment

\begin{tabular}{|c|c|c|c|c|c|c|c|c|c|}
\hline \multirow[b]{2}{*}{$\begin{array}{l}\text { ECw Konuları } \\
\text { ECW Threadmen }\end{array}$} & \multirow[t]{2}{*}{$\mathrm{pH}$} & \multirow{2}{*}{$\begin{array}{c}E C \\
\left(\mathrm{dS} \mathrm{m}^{-1}\right)\end{array}$} & $\mathrm{Na}^{+}$ & $\mathrm{K}^{+}$ & $\mathrm{Ca}^{++}+\mathrm{Mg}^{++}$ & $\mathrm{Cl}^{-}$ & $\mathrm{SO}_{4}^{-}$ & \multirow[t]{2}{*}{ SAR } & \multirow{2}{*}{$\begin{array}{l}\text { Sulama suyu } \\
\text { sinıfı } \\
\text { Irrigation water } \\
\text { class }\end{array}$} \\
\hline & & & & & $\left(\mathrm{me} \mathrm{L}^{-1}\right)$ & & & & \\
\hline $\mathrm{T} 1$ & 7.58 & 0.38 & 0.45 & 0.07 & 2.94 & 0.25 & 0.23 & 0.37 & $\mathrm{~T} 2 \mathrm{~A} 1$ \\
\hline $\mathrm{T} 2$ & 7.30 & 1.1 & 2.25 & 0.20 & 8.93 & 2.50 & 0.89 & 1.06 & T3A1 \\
\hline T3 & 7.22 & 2.5 & 5.07 & 0.37 & 21.83 & 17.5 & 2.33 & 1.53 & T4A1 \\
\hline T4 & 7.30 & 5.0 & 5.42 & 0.59 & 40.56 & 30.0 & 3.57 & 1.20 & T4A1 \\
\hline
\end{tabular}

ECw: Sulama suyu tuzluluğu

T1 sulama konusu için kullanılan su kaynağı Kırklareli baraj suyu (EC 0.38 dS $\left.\mathrm{m}^{-1}\right), \mathrm{T} 2$ sulama konusu için kullanılan su kaynağı Enstitü arazisinde bulunan derin kuyudan (EC $1.1 \mathrm{dS} \mathrm{m}^{-1}$ ) sağlanmıştır. T3 ve T4 sulama konuları için kullanılan sular ise 5 ton'luk su tanklarında, çeşitli tuzların baraj suyuna belli oranlarda karıştırılması ile elde edilmiştir. T3 ve T4 sulama konularının oluşturulmasında kullanılan tuzlar ve miktarları Çizelge 4'te verilmiştir. Sulama seviyeleri oluşturulurken profildeki mevcut nem seviyesinin tarla kapasitesine getirilmesi için gereken su (\%100) esas alınmış ve sulama seviyeleri S1: \%70, S2: \%100 ve S3: \%130 şeklinde oluşturulmuştur. Kök bölgesine yerleştirilen Decagon 5TE nem sensörleriyle toprakta azalan suyun takibi yapılmış ve her sulamada uygulanacak sulama suyu miktarının hesaplanmasında $60 \mathrm{~cm}$ 'lik toprak profilinden tüketilen su esas alınmıştır. Sulamalar damla sulama yöntemi ile yapılmıştır.

Çizelge 4. T3 ve T4 sulama konularının oluşturulmasında kullanılan tuzlar ve miktarları ( $\mathrm{g} \mathrm{L}^{-1}$ )

Table 4. Quantities of salts added to the water corresponding to the T3 and T4 irrigation water salinity levels $\left(g L^{-1}\right)$

\begin{tabular}{lccccc}
\hline $\begin{array}{l}\text { Sulama konuları } \\
\text { Irrigation subjects }\end{array}$ & $\mathrm{ECW}$ & $\mathrm{SAR}$ & $\mathrm{NaCl}$ & $\mathrm{MgSO}_{4}$ & $\mathrm{CaCl}_{2}$ \\
\hline $\mathrm{T} 3$ & 2.5 & 0.69 & 0.14 & 0.22 & 1.14 \\
\hline $\mathrm{T} 4$ & 5.0 & 0.56 & 0.16 & 0.27 & 2.47 \\
\hline
\end{tabular}

Deneme bölünmüş parseller deneme desenine göre ve sulama suyu tuzluluğu konusu ana parsellerde $\left(\mathrm{T} 1=0.38 \mathrm{dS} \mathrm{m}^{-1}\right.$, $\mathrm{T} 2=1.1 \mathrm{dS} \mathrm{m} \mathrm{m}^{-1}, \mathrm{~T} 3=2.5 \mathrm{dS} \mathrm{m} \mathrm{m}^{-1}, \mathrm{~T} 4=5.0 \mathrm{dS}$ $\left.\mathrm{m}^{-1}\right)$, sulama düzeyi konusu alt parsellerde olacak şekilde, üç tekerrürlü olarak yürütülmüştür. Denemeye konu olan sulama suyu tuzluluğu ve sulama düzeyleri Çizelge 5 'te verilmiştir. 
Çizelge 5. Sulama suyu tuzluluğu ve sulama düzeylerinin dağılımı

Table 5. Main and sub-treatments of the experiment

\begin{tabular}{lccc}
\hline \multirow{2}{*}{$\begin{array}{l}\text { Ana Konular, main plots } \\
\text { Tuz Düzeyleri, ECw }\end{array}$} & \multicolumn{3}{c}{ Su düzeyleri, irrigation water levels } \\
\cline { 2 - 4 } & $\mathrm{S} 1(\% 70)$ & $\mathrm{S} 2(\% 100)$ & $\mathrm{S3}(\% 130)$ \\
\hline $\mathrm{T} 1, \mathrm{EC}_{\mathrm{w}}: 0.38 \mathrm{dS} \mathrm{m}^{-1}$ & $\mathrm{~T} 1 \mathrm{~S} 1$ & $\mathrm{~T} 1 \mathrm{~S} 2$ & $\mathrm{~T} 1 \mathrm{S3}$ \\
$\mathrm{T} 2, \mathrm{EC}_{\mathrm{w}}: 1.1 \mathrm{dS} \mathrm{m}^{-1}$ & $\mathrm{~T} 2 \mathrm{~S} 1$ & $\mathrm{~T} 2 \mathrm{~S} 2$ & $\mathrm{~T} 2 \mathrm{~S} 3$ \\
$\mathrm{~T} 3, \mathrm{EC}_{\mathrm{w}}: 2.5 \mathrm{dS} \mathrm{m}^{-1}$ & $\mathrm{~T} 3 \mathrm{~S} 1$ & $\mathrm{~T} 3 \mathrm{~S} 2$ & $\mathrm{~T} 3 \mathrm{~S} 3$ \\
$\mathrm{~T} 4, \mathrm{EC}_{\mathrm{w}}: 5.0 \mathrm{dS} \mathrm{m}^{-1}$ & $\mathrm{~T} 4 \mathrm{~S} 1$ & $\mathrm{~T} 4 \mathrm{~S} 2$ & $\mathrm{~T} 4 \mathrm{S3}$ \\
\hline
\end{tabular}

ECw: Sulama suyu tuzluluğu

Araştırmada bitki materyali olarak; sıralı olarak $0.8 \mathrm{~m}$ sıra arası ve $0.5 \mathrm{~m}$ sıra açık tarla ve sera koşullarına uygun, üzeri mesafelerle dikilmiştir. Üç yıllık yuvarlak ve sert meyveli, meyve ağırlığı 180-190 g olan 'Swanson F1' domates dikim, sulama ve hasat tarihleri Çizelge çeşidi kullanılmıştır. Domates fideleri, tek $6^{\prime}$ da verilmiştir.

Çizelge 6. 2014, 2015 ve 2016 yıllarında denemenin yürütüldüğü döneme ait dikim, hasat ve sulama takvimi

Table 6. Scheduling of planting, harvesting and irrigation during tomato cropping cycle in 2014, 2015 and 2016

\begin{tabular}{cccccc}
\hline $\begin{array}{c}\text { Deneme } \\
\text { yılı } \\
\text { Years }\end{array}$ & $\begin{array}{c}\text { Seraya } \\
\text { dikim } \\
\text { Planting }\end{array}$ & $\begin{array}{c}\text { Illk } \\
\text { sulama } \\
\text { First irrigation }\end{array}$ & $\begin{array}{c}\text { Son } \\
\text { sulama } \\
\text { Last irrigation }\end{array}$ & $\begin{array}{c}\text { Hasat } \\
\text { başlangıcı } \\
\text { Harvest } \\
\text { beginning }\end{array}$ & $\begin{array}{c}\text { Hasat } \\
\text { sonu }\end{array}$ \\
\hline 2014 & 21 Nisan & 08 Mayıs & 09 Eylül & 12 Temmuz & 16 Eylül \\
\hline 2015 & 21 Nisan & 11 Mayıs & 04 Eylül & 09 Temmuz & 09 Eylül \\
\hline 2016 & 15 Nisan & 29 Nisan & 23 Ağustos & 01 Temmuz & 29 Ağustos \\
\hline
\end{tabular}

Gübreleme takvimine uygun olması için haftada iki kez olmak üzere; 2014 yılında 36, 2015 yılında 38 ve 2016 yılında 36 kez sulama yapılmıştır. Bu sulamalarla S1, S2 ve S3 sulama düzeylerinde uygulanan su miktarları; 2014 yılında sırasıyla 250, 350 ve $452 \mathrm{~mm}, 2015$ yılında sırasıyla 291, 407 ve $522 \mathrm{~mm}$, 2016 yılında sırasıyla; 178, 245 ve 312 $\mathrm{mm}$ olarak kaydedilmiştir.

Her parsele uygulanacak sulama suyu miktarı aşağıdaki eşitlik yardımıyla hesaplanmıştır (Kanber ve ark., 1999).

$$
I=(T K-P W) \times A s \times D \times A
$$

Eşitlikte;

I: Sulama suyu miktarı (L), TK: Tarla kapasitesi, Pw: Sulamadan önce etkili kök derinliğinde tarla kapasitesindeki su miktarı ( $\left.\mathrm{g} \mathrm{g}^{-1}\right)$, As: Hacim ağırlığı $\left(\mathrm{g} \mathrm{cm}^{-3}\right)$, D: Etkili kök derinliği $(\mathrm{mm}), \mathbf{A}$ : Parsel alanı $\left(\mathrm{m}^{2}\right)$ değerlerini ifade etmektedir

Bitki su tüketimlerinin hesaplanmasında bitkilerin $60 \mathrm{~cm}$ 'lik toprak profilinden tükettiği su esas alınmış ve aşağıda verilen eşitlikten yararlanılmıştır (Beyce ve ark., 1972). 
$E T=I+P \pm \Delta s$

Eşitlikte;

ET: Bitki su tüketimi $(\mathrm{mm})$, I: Vejetasyon periyodu boyunca uygulanan sulama suyu miktarı ( $\mathrm{mm})$, P: Vejetasyon periyodu boyunca düşen yağış miktarı (mm) (kapalı alan olduğu için yağış dikkate alınmamıştır), $\Delta \mathbf{s}$ : Kök bölgesi toprak nemindeki değişimler $(\mathrm{mm})$ değerlerini ifade etmektedir.

Bitkilerin su kullanım etkinliklerinin (WUE) hesaplanmasında aşağıda verilen eşitlikten yararlanılmıştır (Kanber, 1999).

WUE $=E y / E T, I W U E=E y / I$

Eşitlikte;

Ey: Ekonomik verim (birim alandan elde edilen verim), ET: Bitki su tüketimi (mm), I: Sulama suyu miktarı $(\mathrm{mm})$ değerlerini ifade etmektedir.

Her yıl deneme kurulmadan önce bir önceki yılda toprakta biriken tuzları uzaklaştırmak amacıyla yıkama yapılmıştır. Yıkama suyu ihtiyacının hesaplanmasında aşağıda verilen eşitlikten yararlanılmıştır.

Dys/Dt=(1/(5*(ECes/ECeö)))+0.15

Eşitlikte;

Dys: Yıkama suyu gereksinimi $(\mathrm{mm}), \mathrm{Dt}$ : Toprak derinliği $(\mathrm{cm})$, ECeö: Ilgili derinlikteki toprağın yıkama öncesi elektriksel iletkenliği ( $\mathrm{dS} \mathrm{m}^{-1}$ ), ECes: ilgili derinlikteki toprağın yıkama sonrası elektriksel iletkenliği ( $\mathrm{dS} \mathrm{m}^{-1}$ ) değerlerini ifade etmektedir.
Üç yıllık araştırmadan elde edilen verilerin değerlendirilmesinde $R$ paket (1.2-8) programı kullanılmış ve agricolae kütüphanesinden yararlanılmıştır (De Mendiburu, 2017). Her yıldan elde edilen değerler için Levene ve Bartlett homojenlik testleri yapılmış, dağılım homojen bulunduğu için üç yıllık verilerin toplu varyans analizi yapılmıştır. Grupların karşılaştırılması LSD testine göre \%5 önem seviyesinde yapılmıştır.

\section{Araştırma Bulguları ve Tartışma}

Üç yılın verilerinin ayrı ve toplu değerlendirildiği analizlere göre pazarlanabilir verim sulama suyu düzeylerinden etkilenmiştir (2014, $P<0.001 ; 2015, P<0.001 ; 2016, P<0.001$; toplu, $\mathrm{P}<0.001)$. S2 ve S3 konulu uygulamalarda verimler arasındaki farklar istatistiki anlamda önemli bulunmazken, S1 konulu uygulamalarda verim düşmüştür (Çizelge 7). Toplu varyans analizine göre \%100 ve $\% 130$ sulamalarda verimler sırasıyla 9124 ve 9 $342 \mathrm{~kg} \mathrm{da}^{-1}$ olurken, \%70 sulamada verim $6491 \mathrm{~kg} \mathrm{da}^{-1}$ olarak kaydedilmiştir.

Yine üç yılın verilerinin ayrı ve toplu değerlendirildiği analizlere göre sulama suyunun elektriksel iletkenliği pazarlanabilir verimi etkilemiştir (2014, $\mathrm{P}<0.013 ; 2015, \mathrm{P}<0.001 ; 2016, \mathrm{P}<0.001$; toplu, $P<0.001$ ) (Çizelge 7).

Denemenin ilk yılında sulama suyu tuzluluğu arttıkça verim düşmüş ancak 2.50 ve $5.00 \mathrm{dS} \mathrm{m}^{-1}$ tuz düzeylerinde verimler arasındaki farklar istatistiksel bakımdan anlamlı bulunmamıştır.

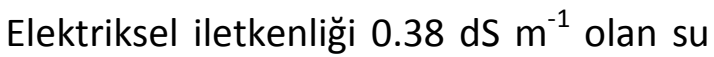


ile (T1) ile sulanan bitkilerde dekara verim $9744 \mathrm{~kg}$ ile en yüksek bulunurken,

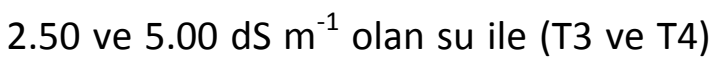
ile sulanan bitkilerde dekara verim sırasıyla 7936 ve $7559 \mathrm{~kg}$ ile en düşük bulunmuştur. Denemenin ikinci yılında sulama suyu tuzluğunun verim üzerine etkisi ilk yıldan farklı olmuş, $0.38,1.10$ ve $2.50 \mathrm{dS} \mathrm{m}^{-1}$ tuzluluk seviyelerindeki sularla sulanan bitkilerin verimleri arasındaki fark istatistiksel bakımdan anlamlı bulunmamıştır. Üçüncü yılda 0.38 ve $1.10 \mathrm{dS} \mathrm{m}^{-1}$ tuzluluk seviyelerindeki sularla sulanan bitkilerin verimleri bir grupta, 2.50 ve $5.00 \mathrm{dS} \mathrm{m^{-1 }}$ tuzluluk seviyelerindeki sularla sulanan bitkilerin verimleri diğer grupta yer almıştır. Üç yılın verilerinin toplu değerlendirilmesinde de ilk yıla benzer sonuçlar elde edilmiş, yine sulama suyu tuzluluğu arttıkça verimin düştüğü ancak T1 $\left(0.38 \mathrm{dS} \mathrm{m}^{-1}\right)$ ve T2 (1.1 dS $\left.\mathrm{m}^{-1}\right)$ tuz seviyelerinde sağlanan verimler arasındaki fark anlamlı bulunmamıştır. Sulama suyu tuzluluğunun $0.38 \mathrm{dS} \mathrm{m}^{-}$ ${ }^{1 \text { 'den }} 1.10 \mathrm{dS} \mathrm{m}^{-1}$ ye (T2) çıkması durumunda yaklaşık \%3.6; $2.50 \mathrm{dS} \mathrm{m}^{-1}$ ye (T3) çıkması durumunda yaklaşık \%15.2 ve $5.00 \mathrm{dS} \mathrm{m}^{-1}$ ye çıkması durumunda da yaklaşık \%26.1 verim kaybı olmuştur.

Çizelge 7. Sulama suyu tuzluluğu ve sulama düzeylerinin pazarlanabilir meyve verimine etkisi $\left(\mathrm{kg} \mathrm{da}^{-1}\right)$ Table 7. Effects of irrigation water salinity and irrigation water volume on on marketable yield $\left(\mathrm{kg} \mathrm{da}^{-1}\right)$

\begin{tabular}{|c|c|c|c|c|c|c|}
\hline \multirow{2}{*}{$\begin{array}{l}\text { Yetiştirme } \\
\text { dönemi } \\
\text { Year }\end{array}$} & \multirow{2}{*}{$\begin{array}{l}\text { Sulama düzeyi } \\
\text { Irrigation levels }\end{array}$} & \multicolumn{5}{|c|}{$\begin{array}{c}\text { Sulama suyu tuzluluğu }\left(\mathrm{dS} \mathrm{m}^{-1}\right) \\
E C W\end{array}$} \\
\hline & & 0.38 & 1.10 & 2.50 & 5.00 & Ortalama \\
\hline \multirow[t]{4}{*}{2014} & $\% 70$ & 8111 & 7434 & 6865 & 6760 & $7293 B$ \\
\hline & $\% 100$ & 10943 & 9886 & 8381 & 7654 & $9214 \mathrm{~A}$ \\
\hline & $\% 130$ & 10177 & 9338 & 8565 & 8635 & $9086 \mathrm{~A}$ \\
\hline & Ortalama, mean & $9744 \mathrm{~A}$ & $8882 \mathrm{~B}$ & $7936 \mathrm{C}$ & $7559 \mathrm{C}$ & \\
\hline \multirow[t]{4}{*}{2015} & $\% 70$ & 7031 & 7113 & 6631 & 4682 & 6364 B \\
\hline & $\% 100$ & 10868 & 10504 & 8900 & 6478 & $9188 \mathrm{~A}$ \\
\hline & $\% 130$ & 10252 & 10412 & 10376 & 8140 & $9795 \mathrm{~A}$ \\
\hline & Ortalama, mean & $9384 \mathrm{~A}$ & $9343 \mathrm{~A}$ & $8636 \mathrm{~A}$ & $6433 \mathrm{~B}$ & \\
\hline \multirow[t]{4}{*}{2016} & $\% 70$ & $6065 d$ & $6046 \mathrm{~d}$ & $5750 d$ & $5407 d$ & 5817 B \\
\hline & $\% 100$ & 10907 a & $10741 \mathrm{a}$ & $7583 c$ & 7194 c & $9106 \mathrm{~A}$ \\
\hline & $\% 130$ & $10130 \mathrm{a}$ & $10000 \mathrm{a}$ & $8620 \mathrm{~b}$ & $7833 \mathrm{bc}$ & $9146 \mathrm{~A}$ \\
\hline & Ortalama, mean & $9034 \mathrm{~A}$ & $8929 \mathrm{~A}$ & $7318 \mathrm{~B}$ & $6812 \mathrm{~B}$ & \\
\hline Yıllar ortalaması & $\% 70$ & 7069 e & $6865 \mathrm{e}$ & $6415 \mathrm{e}$ & $5616 f$ & 6491 B \\
\hline \multirow[t]{3}{*}{ Average } & $\% 100$ & 10906 a & $10377 a b$ & $8288 d$ & 7109 e & $9169 \mathrm{~A}$ \\
\hline & $\% 130$ & $10186 a b$ & 9917 bc & $9187 \mathrm{c}$ & $8079 \mathrm{~d}$ & $9342 \mathrm{~A}$ \\
\hline & Ortalama, mean & $9387 \mathrm{~A}$ & $9052 \mathrm{~A}$ & $7963 \mathrm{~B}$ & $6934 \mathrm{C}$ & \\
\hline
\end{tabular}

Artan tuz seviyelerinde domates veriminin azaldığını bildiren birçok çalışma bulunmakla birlikte (Öztürk, 1994; Satti ve Lopez, 1994; Restuccia ve ark., 2002; Gawad ve ark., 2005; Malash ve ark., 2005), söz konusu kayıpların başladığı tuz seviyeleri ile ilgili bildirişler farklılık göstermektedir. Ayers ve Westcot (1989)'a göre verim kaybı 1.7 dS $\mathrm{m}^{-1}$ den sonra başlarken, Restuccia ve ark. (2002)'na göre $1.6 \mathrm{dS} \mathrm{m}^{-1}$ den sonra başlamıştır. Pascale ve ark. (2003) 4.4 dS $\mathrm{m}^{-1}$ den sonra \%10 azalma meydana geldiğini bildirirken, Gawad ve ark. 
(2005)'na göre 8 dS $\mathrm{m}^{-1}$ tuzluluk seviyesine sahip sulama suyu ile verim azalışı \%50 olmuştur. Tuzluluğun verim ve büyüme üzerine etkisi; özellikle sulama sistemi (Flowers ve ark., 2005; Marchese ve ark., 2005) olmak üzere sulama suyu tuzluluğu, evapotransprasyon, kültürel uygulamalar ve genotip (Maggio ve ark., 2004; ReinaSanchez ve ark., 2005) gibi etkenlere bağlı olarak değişiklik gösterebilmektedir. Domates türleri ve bunların aksesyonları arasında tuza tolerans farkları bulunduğu gibi tür içinde de farklar görülebilmektedir (Romero-Aranda ve ark. 2001; Maggio ve ark., 2004). İri meyveli çeşitlerde verim kaybı küçük meyvelilerden (Cuartero ve FernandezMunoz, 1999; Marchese ve ark., 2008) daha fazla olabilmektedir. Damla sulama, salma sulamaya göre, daha sık uygulandığı ve böylece toprak su içeriği daha yüksek seviyelerde tutulduğu için ozmotik basınç daha az olmakta ve tuzluluğun su alımı üzerine negatif etkisi de azalmaktadır (Marchese ve ark., 2008).

Reina-Sanchez ve ark. (2005)'na göre tuzluluğa bağlı verim azalışlarının nedenleri meyve ağırlığı ve meyve sayısıdır, ancak bu iki faktörün oransal etkisi çeşitlere göre değişiklik göstermektedir. Bazı çeşitlerde birincil faktör meyve ağırlığındaki azalışlar olurken, diğer çeşitlerde etki oranı yüksek olan faktör meyve sayısı olmuştur. Flowers ve ark. (2005)'nın bildirdiğine göre; pazarlanabilir verimde tuzluluğa bağlı düşüş üzerine meyve ağırlığının etkisi \%30 iken, meyve sayısının etkisi \%9 ve çiçek burnu çürük meyve oluşumunun oranı $\% 6$ olmuştur.

Sulama suyu miktarı ile tuzluluğunun pazarlanabilir verim üzerine birlikte etkisi 2016 yılı ve üç yılın birlikte değerlendirdiği durumda önemli bulunmuştur $(P<0.001)$. Üç yıllık verilerin birlikte değerlendirildiği analize göre 2.5 ve $5.0 \mathrm{dS} \mathrm{m}^{-1}$ tuz seviyelerinde uygulanan su miktarı arttıkça verim artmıştır. Diğer yandan, 0.38 ve $1.10 \mathrm{dS} \mathrm{m}^{-1}$ tuz düzeylerinde, sulama düzeyi $\% 70$ 'den \%100'e çıkarıldığında verim artarken, \%130'a çıkarıldığında azalmıştır (Çizelge 7 ve Şekil 1). En yüksek pazarlanabilir verim, $10906 \mathrm{~kg} \mathrm{da}^{-1}$ ile $0.38 \mathrm{dS} \mathrm{\textrm {m } ^ { - 1 }}$ sulama suyu tuzluluğu ve \%100 sulama düzeyinden (T1S2) sağlanmış, bunu 10 $377 \mathrm{~kg} \mathrm{da}^{-1}$ ile T2S2 ve $10186 \mathrm{~kg} \mathrm{da}^{-1}$ ile T1S3 uygulamaları izlemiştir. En düşük verim ise $5616 \mathrm{~kg} \mathrm{da}^{-1}$ ile $5.00 \mathrm{dS} \mathrm{m} \mathrm{m}^{-1}$ sulama suyu tuzluluğu ve $\% 70$ sulama düzeyinden (T4S1) elde edilmiştir. Tuzluluk artışına bağlı verim kayıpları \%70 sulama seviyesinde \%130 seviyesinden daha az olmuştur. Sulama suyu tuzluluğunun $0.38 \mathrm{dS} \mathrm{m}^{-1}$ den 5.00 dS $\mathrm{m}^{-1}$ ye çıkması durumunda \%70 sulamada kayıp $1453 \mathrm{~kg} \mathrm{da}^{-1}$ iken \%130 sulamada $2107 \mathrm{~kg} \mathrm{da}^{-1}$ olmuştur. T1S2'ye (kontrol) göre nispi verim kayıplarında da aynı eğilim görülmüştür. Artan tuzluluğa göre nispi verimler; \%130 sulamada \%93.40'tan \%74.08'e, \%100 sulamada \%100'den \%65.18'e, \%70 sulamada \%64.82'den \%51.50'ye düşmüştür (Şekil 1).

Bir başka deyişle 2.50 dS $\mathrm{m}^{-1}$ in altındaki tuz seviyelerinde \%100 sulamada verimde önemli kayıplar 
meydana gelmemiş ancak bu tuz seviyelerinde sulamanın \%130'a çıkarılması durumunda verim düşmüştür. Diğer yandan $2.50 \mathrm{dS} \mathrm{m}^{-1}$ ve üzerindeki tuz seviyelerinde \%130 sulamalar ile verimin iyileştiği görülmüştür. Benzer şekilde Flowers ve ark. (2005) 2.00 dS m ${ }^{1}$ 'in altındaki tuz seviyelerinde verimi etkilemediğini ve yüksek tuz seviyelerinde ilave sulamanın verimi iyileştirici etkisi olduğunu bildirmişlerdir.

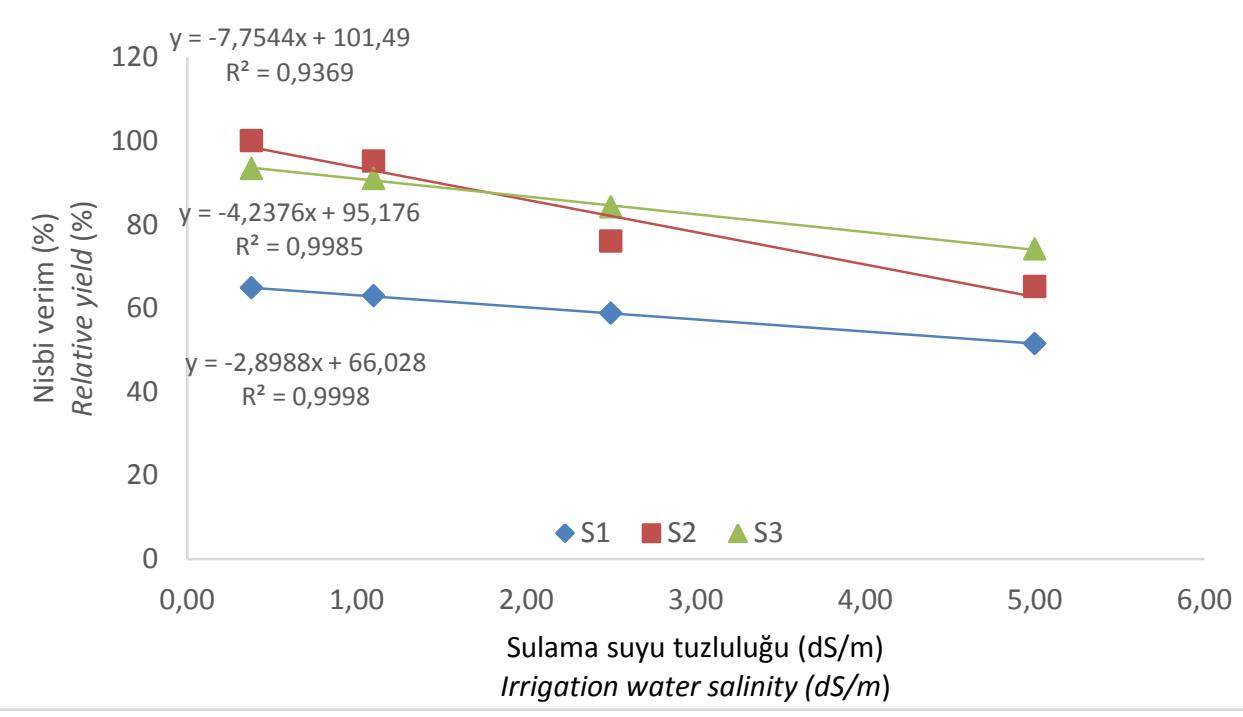

Şekil 1.Sulama suyu tuzluluğu, sulama düzeyi ve nispi verim arasındaki ilişkiler (nispi verim yüzdesinin hesaplanması sulama suyu tuz seviyesinin $0.38 \mathrm{dS} \mathrm{m}^{-1}$ ve sulama düzeyinin $\% 100$ (S2) olduğu durumda sağlanan verimler esas alınmıştır)

Figure 1. Relations between relative yield, irrigation water salinity and applied irrigation levels (relative yield was calculated based on the yield of plants from $100 \%$ restoring of field capacity (S2) with ECW of $0.38 \mathrm{dS} \mathrm{m}^{-1}$ )

Bir çok araştırmanın sonuçlarına benzer şekilde (Romera-Aranda ve ark., 2001; Flowers ve ark., 2005; ReinaSanchez ve ark., 2005; Yurtseven ve ark., 2005) sulama suyu tuzluluğu arttıkça bitki su tüketimlerinde azalma olduğu görülmüştür. Flowers ve ark. (2005)'na göre tuzlu olmayan koşullarda kg verim başına tüketilen su 20 litre iken, $50 \mathrm{mM}$ $\mathrm{NaCl}$ ilave edilmiş çözelti uygulanan bitkilerde tüketim 31 litre olmuştur. Reina-Sanchez ve ark., (2005)'na göre tuzluluk artışına bağlı olarak su alımında azalma ve bunun sonucu verim kaybının muhtemel nedeni bitkinin stres koşulları altında aldığı suyu öncelikle transprasyon ve vegetatif büyüme için harcaması ve meyve büyümesinin ikinci plana atılmasıdır. Diğer yandan Maggio ve ark., (2004)'na göre, ülkemizin de içinde bulunduğu iklim kuşağında ilkbahar yaz döneminde yetiştirilen domateslerde, verim kaybının nedeni tuzdan ziyade yüksek sıcaklık ve düşük nem gibi çevre faktörlerinin teşvik ettiği meyve sayısı ve çapındaki azalmalardır. 
Sulama suyu elektriksel iletkenliğinin $0.38 \mathrm{dS} \mathrm{m}^{-1 \text { ' }}$ den $5.00 \mathrm{dS} \mathrm{m}^{-1}$ e yükselmesi durumunda su tüketiminde azalışlar; üç yılın ortalamasına göre $\% 70$ sulamada 52 $\mathrm{mm} \mathrm{da}{ }^{-1}, \% 100$ sulamada $74 \mathrm{~mm} \mathrm{da}^{-1}$ ve \%130 sulamada $65 \mathrm{~mm} \mathrm{da}{ }^{-1}$ şeklinde gerçekleşmiştir (Çizelge 8). Diğer yandan $\% 70$ ve $\% 100$ sulama düzeylerinde 0.38 ve $1.1 \mathrm{dS} \mathrm{m}^{-1}$ elektriksel iletkenliğe sahip sularla yapılan sulamalarda tüketilen su, uygulanan sudan fazla iken $2.5 \mathrm{dS} \mathrm{m}^{-1}$ ve üzeri tuzlarda tüketilen su miktarı uygulanan su miktarından az olmuştur. Kaybedilen suyun \%130'unun uygulandığı durumda ise tüm sulama suyu tuzluluğu düzeylerinde tüketilen su uygulanan su miktarından düşüktür. Deneme alanı yağışlara kapalı olduğu ve evapotransprasyonun arttığı dönemde gölgeleme yapıldığı için su tüketimleri ile uygulanan su miktarı arasındaki farklar sulama suyu tuzluluğu ve sulama düzeylerine bağlanabilir.

Sulama suyu kullanım etkinliği (IWUE) hem 2.50 hem de $5.00 \mathrm{dS} \mathrm{m}^{-1}$ seviyelerinde uygulanan su miktarı arttıkça azalmakta iken 0.38 ve $1.1 \mathrm{dS} \mathrm{m}^{-1}$ seviyelerinde en düşük IWUE \%130 sulama düzeyinde kaydedilmiştir (Çizelge 8).

Su kullanım etkinliği (WUE) $24.7 \mathrm{~kg} \mathrm{da}^{-}$ ${ }^{1} \mathrm{~mm}^{-1}$ (T4S3) ile $31.7 \mathrm{~kg} \mathrm{da}^{-1} \mathrm{~mm}^{-1}$ (T1S2) arasında değişiklik göstermiştir. Su kullanım etkinliğinin en yüksek verimin

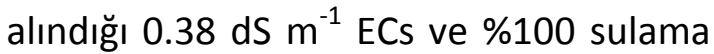

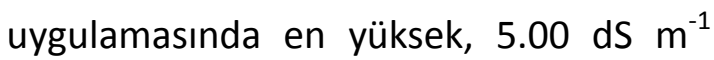
ECs ve \%130 sulama uygulamasında en düşük olduğu görülmüştür. Bu bulgudan farklı olarak Patane ve ark. (2011) \%100 sulamada WUE'nin \%50 sulamadan düşük olduğunu bildirmişlerdir. Bizim çalışmamızda en düşük tuz seviyesinde de durum diğer tuz seviyelerine benzer olduğu için bu farkın sulama suyu tuzluluğundan ziyade sulama uygulamaları arasındaki verim farkları, sulama zamanı, uygulanan su miktarları ve sulama aralıkları gibi nedenlerden kaynaklandığı söylenebilir. Araştırıcılar \%100 sulamada yıllara göre sırasıyla yaklaşık 379 ve $381 \mathrm{~mm}$, \%50 sulamada yıllara göre sırasıyla yaklaşık 211 ve 197 mm suyu ilk sezon 10, ikinci sezon 11 seferde uygularken bu çalışmada \%100 sulamada $334 \mathrm{~mm} \% 70$ sulamada 240 $\mathrm{mm}$ su ortalama 36 seferde uygulanmıştır. íki çalışmada sulama zamanlarının farklı olması yanında sulama uygulamalarına göre pazarlanabilir verimler arasındaki farklar daha fazla, uygulanan su miktarları arasındaki farklar da daha azdır.

Reina-Sanchez ve ark., (2005) su kullanım etkinliğinin bitkinin içinde bulunduğu çevre koşullarından ve hasat periyodunun uzunluğundan etkilendiğini, Flowers ve ark. (2005) da sulama sıklığı artırmanın toprakta tuz birikiminin azalttığını ve verimde artış sağladığını bildirmişlerdir.

Sulama suyu tuzluluğu ve su düzeylerinin birlikte etkisine göre $\% 70$ ve \%130 sulama düzeylerinde su kullanım etkinlikleri arasındaki farkın en yüksek olduğu $\left(2.0 \mathrm{~kg} \mathrm{da}^{-1} \mathrm{~mm}^{-1}\right)$ tuz seviyesi $2.50 \mathrm{dS} \mathrm{m}^{-1}$, en düşük olduğu $\left(0.2 \mathrm{~kg} \mathrm{da}^{-1}\right.$ $\mathrm{mm}^{-1}$ ) tuz seviyesi ise $0.38 \mathrm{dS} \mathrm{m}^{-1^{\prime}}$ dir. Buradan yola çıkarak; 2.50 ve $5.00 \mathrm{dS} \mathrm{m}^{-1}$ tuz düzeylerinde uygulanan su miktarının artışına paralel olarak verimin arttığı 
ancak su kullanım etkinliğinin \%100 sulamanın üzerindeki sulamalarda düşüş gösterdiği diğer yandan, her tuz seviyesinde, \%70 sulama düzeyinde sağlanan su kullanım etkinliğinin \%130'a göre yüksek olduğu söylenebilir.

Sulama suyu tuzluluğu ve su kullanım etkinliği arasındaki ilişkiye göre sulama suyu tuzluluğu arttıkça WUE azalmıştır. En yüksek pazarlanabilir verimin alındığı $0.38 \mathrm{dS} \mathrm{m}^{-1}$ tuzluluk seviyesinde WUE'nin $27.9 \mathrm{~kg} \mathrm{da}^{-1} \mathrm{~mm}^{-1}$ olurken en düşük verimin alındığı $5.00 \mathrm{dS} \mathrm{m}^{-1}$ tuz seviyesinde $25.5 \mathrm{~kg} \mathrm{da}^{-1} \mathrm{~mm}^{-1}$ olmuştur. $\mathrm{Bu}$ sonuçtan farklı olarak Wan ve ark. (2007) elektriksel iletkenliği 1.1 ile 4.9 dS $\mathrm{m}^{-1}$ arasında olan suların verim üzerine etkisinin çok az olduğunu ancak IWUE ile WUE'nin arttığını bildirmişlerdir.
Araştırıcılar sulama suyu tuzluluğunun verim üzerine etkisinin az oluşunu yağışların sık ve kuvvetli olmasına bağlarken tuzlu suların dikimden 30 gün sonra kullanılmaya başlanmasının da önemli olduğunu vurgulamışlardır.

Sulama suyu düzeyi ile su kullanım etkinliği arasındaki ilişkiye bakıldığında; en yüksek pazarlanabilir verimlerin alındığı $\% 130$ ve $\% 100$ sulamalarda su kullanım etkinliklerinin sırasıyla 25.7 ve $28.9 \mathrm{~kg} \mathrm{da}^{-1} \mathrm{~mm}^{-1}$, en düşük verimin alındığı \%70 sulama uygulamasında ise $26.4 \mathrm{~kg} \mathrm{da}^{-1} \mathrm{~mm}^{-1}$ olduğu görülmüştür. Görüldüğü gibi sadece sulama uygulamalarının etkisi dikkate alındığında da \%70 sulamalarda WUE \%130 sulamadan yüksek olmuştur. 
Çizelge 8. Sulama suyu tuzluluğu (SST, dS $\mathrm{m}^{-1}$ ) ve sulama düzeylerinin (SD) uygulanan su miktarı (Ir, mm), su tüketimi (ET, mm), sulama suyu kullanım etkinliği (IWUE, $\mathrm{kg} \mathrm{da}^{-1} \mathrm{~mm}^{-1}$ ), su kullanım etkinliği (WUE, $\mathrm{kg} \mathrm{da}^{-1} \mathrm{~mm}^{-1}$ ) ve pazarlanabilir verim/toplam verim (PV/TV, \%) oranı üzerine etkisi

Table 8. Effects of irrigation water salinity ( $\mathrm{ECW}, \mathrm{dS} \mathrm{m}^{-1}$ ) and irrigation levels (IL) on applied water amount (Ir, $\left.\mathrm{mm}\right)$, water consumption (ET, mm), water use efficiency (WUE, $\mathrm{kg} \mathrm{da}^{-1} \mathrm{~mm}^{-1}$ ), irrigation water use efficiency (IWUE, $\mathrm{kg} \mathrm{da}^{-1} \mathrm{~mm}^{-1}$ ) and marketable yield/total yield (MY/TY, \%)

\begin{tabular}{|c|c|c|c|c|c|c|c|c|c|c|c|c|c|c|c|c|c|c|}
\hline \multirow{2}{*}{$\begin{array}{l}\text { SST } \\
E C W\end{array}$} & \multirow{2}{*}{$\begin{array}{l}\text { SD } \\
I L\end{array}$} & \multicolumn{4}{|l|}{2014} & \multicolumn{4}{|l|}{2015} & \multicolumn{4}{|l|}{2016} & \multicolumn{5}{|c|}{ Üç Yıllık Ortalama, average } \\
\hline & & Ir & ET & IWUE & WUE & Ir & ET & IWUE & WUE & Ir & ET & IWUE & WUE & Ir & ET & IWUE & WUE & $\begin{array}{l}\mathrm{PV} / \mathrm{TV} \\
M Y / T Y\end{array}$ \\
\hline \multirow[t]{3}{*}{0.38} & $\% 70$ & 250 & 253 & 32.4 & 32.1 & 291 & 341 & 24.2 & 20.6 & 178 & 220 & 34.1 & 27.6 & 240 & 271 & 29.5 & 26.1 & 85.2 \\
\hline & $\% 100$ & 350 & 332 & 31.3 & 33.0 & 407 & 420 & 26.7 & 25.9 & 245 & 281 & 44.5 & 38.8 & 334 & 344 & 32.7 & 31.7 & 96.1 \\
\hline & $\% 130$ & 452 & 345 & 22.5 & 29.5 & 522 & 516 & 19.6 & 19.9 & 312 & 319 & 32.5 & 31.8 & 429 & 393 & 23.7 & 25.9 & 92.0 \\
\hline \multirow[t]{3}{*}{1.10} & $\% 70$ & 250 & 240 & 29.7 & 31.0 & 291 & 313 & 24.4 & 22.7 & 178 & 214 & 34.0 & 28.3 & 240 & 256 & 28.6 & 26.8 & 84.8 \\
\hline & $\% 100$ & 350 & 329 & 28.2 & 30.0 & 407 & 416 & 25.8 & 25.2 & 245 & 276 & 43.8 & 38.9 & 334 & 340 & 31.1 & 30.5 & 94.6 \\
\hline & $\% 130$ & 452 & 347 & 20.7 & 26.9 & 522 & 500 & 19.9 & 20.8 & 312 & 311 & 32.1 & 32.2 & 429 & 386 & 23.1 & 25.7 & 93.6 \\
\hline \multirow[t]{3}{*}{2.50} & $\% 70$ & 250 & 226 & 27.5 & 30.4 & 291 & 296 & 22.8 & 22.4 & 178 & 190 & 32.3 & 30.3 & 240 & 237 & 26.7 & 27.0 & 80.4 \\
\hline & \%100 & 350 & 302 & 23.9 & 27.8 & 407 & 385 & 21.9 & 23.1 & 245 & 239 & 31.0 & 31.7 & 334 & 309 & 24.8 & 26.9 & 91.4 \\
\hline & $\% 130$ & 452 & 331 & 18.9 & 25.9 & 522 & 481 & 19.9 & 21.6 & 312 & 291 & 27.6 & 29.6 & 429 & 368 & 21.4 & 25.0 & 90.2 \\
\hline \multirow[t]{3}{*}{5.00} & $\% 70$ & 250 & 205 & 27.0 & 33.0 & 291 & 286 & 16.1 & 16.4 & 178 & 166 & 30.4 & 32.6 & 240 & 219 & 23.4 & 25.6 & 80.3 \\
\hline & $\% 100$ & 350 & 257 & 21.9 & 29.8 & 407 & 357 & 15.9 & 18.1 & 245 & 195 & 29.4 & 36.9 & 334 & 270 & 21.3 & 26.4 & 87.3 \\
\hline & $\% 130$ & 452 & 289 & 18.3 & 28.6 & 522 & 450 & 15.6 & 18.1 & 312 & 244 & 25.1 & 32.1 & 429 & 328 & 18.1 & 24.7 & 90.0 \\
\hline 0.38 & & - & 310 & - & 31.4 & - & 426 & - & 22.8 & - & 273 & - & 33.1 & - & 336 & - & 27.9 & 91.1 \\
\hline 1.10 & & - & 305 & - & 29.1 & - & 410 & - & 22.8 & - & 267 & - & 33.4 & - & 327 & - & 27.7 & 91.0 \\
\hline 2.50 & & - & 286 & - & 27.8 & - & 387 & - & 22.3 & - & 240 & - & 30.5 & - & 305 & - & 26.1 & 87.3 \\
\hline \multirow[t]{4}{*}{5.00} & & - & 250 & - & 30.2 & - & 364 & - & 17.7 & - & 202 & - & 33.7 & - & 272 & - & 25.5 & 85.6 \\
\hline & $\% 70$ & 250 & 231 & 29.2 & 31.6 & 291 & 309 & 21.9 & 20.6 & 178 & 198 & 32.7 & 29.3 & 240 & 246 & 27.0 & 26.4 & 82.7 \\
\hline & $\% 100$ & 350 & 305 & 26.3 & 30.2 & 407 & 396 & 22.6 & 23.2 & 245 & 248 & 37.2 & 36.7 & 334 & 316 & 27.5 & 29.0 & 92.3 \\
\hline & $\% 130$ & 452 & 328 & 20.1 & 27.7 & 522 & 487 & 18.8 & 20.1 & 312 & 291 & 29.3 & 31.4 & 429 & 367 & 21.8 & 25.5 & 91.5 \\
\hline
\end{tabular}




\section{Sonuç ve Öneriler}

Sulama suyu elektriksel iletkenliği ve sulama düzeyi ayrı ayrı ve birlikte değerlendirildiğinde aşağıdaki sonuçlara ulaşılmıştır;

-Sulama suyu tuzluluğu arttıkça her sulama düzeyinde verim düşmüştür. Sulama suyu tuzluluğunun artışına bağlı verim kaybı en fazla \%100 sulamada görülmüştür.

-Etkili kök derinliğinde eksilen suyu tarla kapasitesine getirmek için gereken suyun \%70'inin uygulandığı durumda tüm sulama suyu tuzluluğu düzeylerinde verim kaybı olmuş. Bu kayıplar tuzluluk arttıkça artmış, $5.00 \mathrm{dS} \mathrm{m}^{-1}$ tuz seviyesinde kayıp kontrole göre \%49 olarak gerçekleşmiştir.

-Sulama suyunun elektriksel iletkenliği arttıkça pazarlanabilir verime göre WUE düşmüştür.

-Her tuz seviyesinde en yüksek WUE \%100 sulamalardan elde edilmiştir. Sulama düzeyi $\% 70$ 'den $\% 100$ çıktığında WUE artarken, \%130'a çıktığında \%70 sulama ile sağlananın da altına düşmüştür. Bir başka deyişle \%70 sulama ile sağlanan WUE her tuz seviyesinde \%130 sulamadan yüksek olmuştur.

-Yüksek tuz seviyelerinde WUE arasındaki farklar düşük tuz seviyelerinden daha az olmuştur.

-Sulama suyu elektriksel iletkenliği 2.50

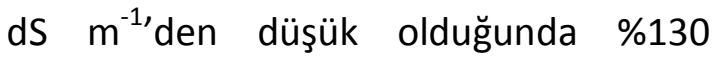
sulamada uygulanan ve tüketilen suya karşılık elde edilen pazarlanabilir verim, IWUE ve WUE'nin düşük olduğu görülmüştür. Buna ilave olarak nispi verim yüzdesi de en fazla \%94 olmuştur.
Diğer yandan \%70 sulamanın IWUE ve WUE'ni olumlu etkilediği görülmüştür.

Bu sonuçlara göre;

Kontrole göre pazarlanabilir verimde

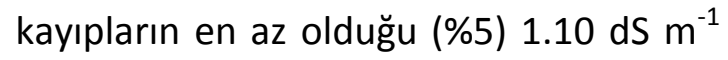
elektriksel iletkenliğe sahip suların Trakya Bölgesi erken ilkbahar-yaz yetiştirme periyodunda sera domates yetiştiriciliğinde kullanılabileceği, bitki su tüketimi ve verim kaybını azaltacak ve su kullanım etkinliğini artıracak teknoloji ve yöntemler benimsenerek $2.50 \mathrm{dS} \mathrm{\textrm {m } ^ { - 1 }}$ elektriksel iletkenliğe sahip suların da yetersiz su koşullarında kullanılabileceği söylenebilir.

\section{Ekler}

Makale, TAGEM tarafından desteklenerek yürütülen TAGEM/TSKAD/14/A13/BO2/08 nolu ve "Farklı Tuzluluk Düzeyindeki Sulama Sularının Serada Yetiştirilen Domates ve Brokkoli'nin Verim-Kalite Parametreleri ve Toprak Profili Tuzluluğuna Etkisi" isimli araştırma projesinden veriler içermektedir.

\section{Kaynaklar}

Ayers. R.S.. Westcot. D.W.. 1989. Water Quality for Agriculture (Irrigation and Drainage Paper). Food and Agriculture Organization of the United Nations. Rome.

Beyce. Ö.. Madanoğlu. K.. Ayla Ç.. 1972. Türkiye'de Yetiştirilen Bazı Sulanır Mahsullerin Su İstihkakları. Merkez Toprak Araştırma Enstitüsü Müdürlüğü Yayınları. Genel Yayın No:15. Ankara.

Cuartero. J.. Fernandez-Munoz. R.. 1999. Tomato and Salinity. Scientia Horticulture, 78: 83125. 
De Mendiburu. F.. 2017. Statistical Procedures for Agricultural Research. $\mathrm{R}$ package version 1.2-8.

Gawad. G. A.. Arslan. A.. Gaihbe. A.. Kadouri. F.. 2005. The Effects of Saline Irrigation Water Management and Salt Tolerant Tomato Varieties on Sustainable Production of Tomato in Syria (19992002). Agricultural Water Management, 78(1): 39-53.

Kanber. R.. 1999. Sulama. Ç.Ü. Ziraat Fakültesi Genel Yayın No:174. Ders Kitapları Yayın No:A-52. Adana

Maggio. A.. De Pascale. S.. Angelino. G.. Ruggiero. C.. Barbieri. G.. 2004. Physiological Response of Tomato to Saline Irrigation in Long-term Salinized Soils. Europ. J. Agronomy, 21: 149-159.

Malash. N.. Flowers. T. J.. Ragab. R.. 2005. Effect of irrigation Systems and Water Management Practices Using Saline and Non-Saline Water on Tomato Production. Agricultural Water Management, 78 (1): 25-38.

Marchese. M.. Tuttobene. R.. Restuccia. A.. Longo. A. M. G.. Mauromicale. G.. Restuccia. G.. 2008. Effects of Electrical Conductivity od Irrigation Water on the Growth and Production of Solanum lycopersicum L. var. cerasiforme Grown in Greenhouse. (In: Irrigation in Mediterranean Agriculture: Challenges and Innovation for The Next Decades. Eds: Santini. A.. Lamaddalena. N.. Severino. G.. Palladino. M.). CIHEM Options Mediterraneans. Series A. Seminaries Mediterraneans; No:84.

Öztürk. A.. 1994. Taban Suyu Derinliği ve Sulama Suyu Kalitesinin Biber Verimine Etkisi. Ankara Üniversitesi Fen Bilimleri Enstitüsü. Doktora Tezi. Ankara.
Pascale. S.. Angelino. G.. Graziani. G.. Maggio. A.. Pascale. S.. 2003. Effect of Salt Stress on Water Relations and Antioxidant Activity in Tomato. Proceedings of the Eighth International ISHS Symposium on the Processing Tomato. Istanbul. Turkey. ActaHorticulturae, 613: 39-46.

Reina-Sanchez. A.. Romero-Aranda. R.. Cuartero. J.. 2005. Plant Water Uptake and Water Use Efficiency of Greenhouse Tomato Cultivars Irrigated with Saline Water. Agricultural Water Management, 78: 5466.

Restuccia. G.. Marchese. M.. Mauromicale. G.. Restuccia. A.. Battaglia. M.. 2002. Yield and Fruit Quality of Tomato Grown in Greenhouse with Saline Irrigation Water. In VI International Symposium on Protected Cultivation in Mild Winter Climate: Product and Process Innovation, 614: 699-704.

Romera-Aranda. R.. Soria. T.. Cuartero. J.. 2001. Tomato Plant-Water Uptake and PlantWater Relationships under Saline Growth Conditions. Plant Science, 160: 265-272.

Satti. S.M.E.. Lopez. M.. 1994. Effect of Increasing Potassium Levels for Alleviating Sodium Chloride Stress on the Growth and Yield of Tomato. Communications Soil Science and Plant Analysis, 25 (15-16): 2807-2823.

Tülücü. K.. 2003. Özel Bitkilerin Sulanması. Çukurova Üniversitesi Ziraat Fakültesi Tarımsal Yapılar ve Sulama Bölümü. Genel Yayın No: 254. Adana.

Yurtseven. E.. Kesmez. G.D.. Ünlükara. A.. 2005. The Effects of Water Salinity and Potassium Levels on Yield. Fruit Quality And Water Consumption of A Native Central Anatolian Tomato Species (Lycopersicun esculentum). Agricultural Water Management, 78: 128-135. 